\title{
The burden of traditional neonatal uvulectomy among admissions to neonatal intensive care units, North Central Ethiopia, 2019: A triangulated crossectional study
}

Wubet Alebachew Bayih ( $\nabla$ wubetalebachew@gmail.com )

Debre Tabor University

Biniam Minuye

Debre Tabor University

Abebaw Yeshambel

Debre Tabor University

Demeke Mesfin

Debre Tabor University

Research article

Keywords: Uvulectomy, Debre Tabor General Hospital

Posted Date: January 22nd, 2020

DOI: https://doi.org/10.21203/rs.2.21584/v1

License: (a) (i) This work is licensed under a Creative Commons Attribution 4.0 International License.

Read Full License 


\section{Abstract}

Background Traditional neonatal uvulectomy is unsupervised, unscientific and potentially dangerous cultural malpractice. This malpractice is often accompanied with life threatening neonatal morbidities such as infection, anemia, aspiration and oropharyngeal injury. However, there is no current regional and even national data about the burden, associated factors and perception of traditional uvulectomy among neonatal admissions to neonatal intensive care units. Methods A quantitative cross sectional study supplemented with phenomenological study was employed on 422 mother-neonate pairs admitted to Debre Tabor General Hospital from September 2018 to August 2019. Eight women who were not included in the quantitative part were involved for the qualitative study. Systematic and purposive sampling methods were used to select study participants for the quantitative and qualitative study respectively. Binary logistic regression models were fitted to declare statistical significance at $p$-value $\leq 0.05$ and $95 \%$ $\mathrm{Cl}$. Result Complications of traditional uvulectomy contributed $15.90 \%$ of the overall neonatal admissions. At admission, most of the victim neonates had septic presentation (88.1\%) followed by anemia (55.2\%). From multivariable analysis, having male neonate [AOR= 4.87; 95\% Cl: 1.10, 21.59], antenatal couple counseling about traditional neonatal uvulectomy [AOR=0.053; 95\% Cl: 0.01, 0.35], home delivery $[A O R=6.02 ; 95 \% \mathrm{Cl}: 1.15,31.61]$, postnatal couple counseling about traditional neonatal uvulectomy [AOR= $0.101 ; 95 \% \mathrm{Cl}: 0.02,0.65]$, prior history of traditional neonatal uvulectomy $[\mathrm{AOR}=7.15$; $95 \% \mathrm{Cl}: 1.18,43.21]$ and knowing at least one disadvantage of traditional neonatal uvulectomy [AOR= $0.068 ; 95 \% \mathrm{Cl}: 0.01,0.44]$ were independent predictors of the malpractice. Furthermore, maternal perception of no modern medicine to treat elongated uvula was the most explained reason to do the malpractice. Conclusion The burden of traditional uvulectomy was high. Fortunately, its predictors are modifiable. Therefore, different community groups including women health development armies, elders, religious fathers, health professionals and criminal prosecutors should be actively mobilized against this malpractice. Besides, parental couple counseling about the key message of no traditional neonatal uvulectomy should be properly implemented in the routine antenatal and postnatal programs of the health care delivery system at south Gondar zone.

\section{Background}

Uvula is a small soft tissue that hangs down from the back of the mouth above the throat between the two tonsils $[1,2]$. It has its own natural advantages of preventing aspiration, lubricationing oropharyngeal mucosa, serving for language communication, boosting immunological function and prevention of breast milk regurgitation through the neonatal nose $[1,3,4]$.

Traditional neonatal uvulectomy is unscientific, unsupervised and potentially dangerous practice that involves partial or total removal of uvula and sometimes the tonsils using unsterilized traditional instruments (sharp blade, horsetail hair or thread with a loop) [1, 5-7]. These instruments are usually used on several neonates in the same session thereby increasing the transmission of communicable infections mainly HIV and hepatitis. Moreover, other common complications (disadvantages) include anemia, hemorrhage, sepsis, jaundice, septicemia, tetanus, neck infection, pharyngeal dryness, aspiration, pain for 
many days after the procedure, change in voice, disturbance in sleep pattern, regurgitation of breast milk from the nostril and cavernous sinus thrombosis $[2,6,8-10]$. Neonatal admissions attributed to these complications require antibiotics, oxygen, intravenous fluid, blood transfusion, phototherapy and greater number of health care providers thereby accelerating the cost in the health care system $[9,11-15]$.

In Africa, neonatal uvulectomy by traditional practitioners has been an age-long practice $[1-4,9,12,14$, 17-21]. The procedure persists in the developing countries probably because of low socioeconomic status and non-formal educational level $[4,18]$. There are divergent views to the reason as well as its overall benefit in these countries. Besides, there have been reported cases of complications after the procedure with a subsequent increase in morbidity and mortality [6, 7, 11, 22-24].

Ethiopian neonatal mortality rate (30/1000) is among the five highest neonatal mortality rate burden countries in the world. Amhara region, the study area, comprised the highest proportion of the national burden (47\%) [9]. Morbidities from the post uvulectomy complications contributed to the magnificent burden of neonatal mortality in the region. This is because unlike other harmful traditional practices, traditional neonatal uvulectomy is still being practiced in the region mainly at South Gondar zone $[9,10]$. Nonetheless, there is no current regional and even national data about the proportion, associated factors and reasons of this malpractice.

\section{Methods}

\section{Study setting and period}

The study was conducted from September 2018 to August 2019 at Debre Tabor General Hospital (DTGH), South Gondar Zone, Amhara region, North Central Ethiopia. The hospital is found $666 \mathrm{~km}$ far from Addis Ababa and $105 \mathrm{~km}$ away from Bahir Dar city. It is the largest hospital in South Gondar zone serving about 2.7 million populations and linked to 7 district hospitals. Neonatal Intensive Care Unit (NICU) of the hospital had a total of 28 neonatal beds and hosted approximately 1159 admissions per year. Other than prematurity and perinatal asphyxia, unknown number of admissions was attributed to the complications of harmful traditional practices like traditional neonatal uvulectomy [10, 25].

\section{Study design and participant characteristics}

Mixed type (quantitative supplemented with qualitative) hospital based cross sectional study was conducted. Phenomenological study design was employed for the qualitative part. All postnatal mothers whose age $\geq 18$ years and lived at least six months in the study area prior to the study and visiting Neonatal Intensive Care Unit (NICU) during the study were eligible. However, abandoned neonates (those neonates left in NICU without mothers), mothers with critical illness or any difficulty of talking/listening, those having psychiatric disorders and known medical problems were excluded since they were not mentally and physically capable of being interviewed. Non volunteer mothers were also excluded.

\section{Sample size determination and sampling procedure}


By using single population proportion formula and considering confidence level /Z/ of 95\%, marginal error of $5 \%$, a reasonable estimate for the proportion of traditional neonatal uvulectomy $(P=0.5)$ and adding a none response rate of $10 \%$, a total sample of 422 mother-baby pairs was obtained. By using systematic sampling, every other eligible mother baby pair admitted to NICU was selected for the quantitative part of the study. The sample size for the qualitative part of the study was determined based on the saturation of information. Thus, 8 women who were not involved in the quantitative study were selected purposively and undergone to In-Depth Interview (IDI).

\section{Measurement and data collection procedure}

For quantitative part of the study, data were collected by four trained BSc neonatal nurses through face to face interview using a validated and structured questionnaire that was developed from reviewing different literatures of traditional uvulectomy and other harmful traditional practices [1-7, 11-21, 26-28]. An interview was made for eligible mother-neonate dyads after admission of their neonate to NICU. The questionnaire contained factors related to maternal socio demography, obstetrics, neonatal health related characteristics and maternal knowledge of uvula and uvulectomy.

Moreover, for qualitative part of the study, the IDI was conducted using a semi-structured interview guide at the last 2 months of the survey by the principal investigator and one supervisor to supplement the quantitative findings and address issues that were not touched by the quantitative part. At the initial interview, open ended questions about the participants' perceptions, reasons and experience of traditional neonatal uvulectomy were raised and then prompt questions were followed as necessary. The principal investigator adequately probed for responses on all aspects of maternal perceptions towards traditional uvulectomy listed in the IDI guide. Each IDI was tape recorded after getting written and signed voluntary consent from the woman and each interview was lasted between 30 and 40 minutes. Those participants were selected by the principal investigator and the interview was conducted until the required information was saturated.

\section{Data Quality control}

The questionnaire was first prepared in English and then translated to local language, Amharic, suitable for data collection. The Amharic version was then retranslated back to English to check for consistency. There was a further possibility that some women did not understand the questions fully, or that difficulties arose in translation. To work on this challenge, two professional translators with medical experience were hired during data cleansing in order to explain the questions and correctly translate maternal answers for minimizing the risk of information loss during translation. The tool was adapted from different studies in Ethiopia [3, 12, 14, 18, 20, 21], Kenya [8], Tanzania [6, 7, 11], Niger [13] and Nigeria $[4,26,28]$.

Five days of training (two days theoretical and three days practical) was first provided for data collectors and supervisors about pretesting and the process of data collection. Before the actual data collection, pretest was done on 21 eligible mother-baby pairs ( $5 \%$ of sample size) at DTGH 2 weeks prior to the study 
just to evaluate the clarity of questions, validity of the tool and reaction of the respondents to the questions. During data collection, data collectors were closely monitored and guided by two MSc neonatal nurse supervisors for complete and appropriate collection of the data. Reporting of the collected data to the principal investigator was made on a daily basis. Furthermore, the collected data were double entered into Epidata version 4.2 by two data clerks and consistency of the entered data were cross checked by comparing the two separately entered data for validation purpose. Besides, to minimize bias, interviews were conducted in an area with adequate confidentiality and privacy without the involvement of health care providers working in that hospital. Double data entry was done by two data clerks. Simple frequencies and cross tabulation were done for missing values and crosschecked with hard copies of the collected data. Each IDI was conducted in a private room and tape recorded, then translated back to English by language experts.

\section{Data processing and analysis}

The double entered data were exported to SPSS version 23 software for data transformation and further analysis. Frequencies, proportion, summary statistics and cross tabulation were used to describe the study population in relation to relevant variables and presented in tables. The assumptions for binary logistic regression model were first checked and then bivariable analysis was carried out to identify candidate variables $(\mathrm{p}<0.25)$ for multivariable analysis. Then, multivariable logistic regression analysis was performed using those candidate variables to investigate statistically significant independent predictors of traditional neonatal uvulectomy by adjusting for possible confounders. Finally, variables whose $p$ value less than $0.05(p<0.05)$ from multivariable logistic regression were declared as statistically significant using adjusted odds ratio of $95 \% \mathrm{Cl}$. Multi-collinearity between the study variables was diagnosed using standard error and correlation matrix. Hoshmer-Lemeshow statistic and Omnibus tests were also performed to test for model fitness. For the qualitative study the in-depth interview was transcribed verbatim in Amharic audios and translated into English by language expert. Data were analyzed using thematic analysis approach. Each transcript was carefully screened and triangulated with the quantitative result.

\section{Ethical consideration}

Ethical clearance was obtained from ethical review committee of Debre Tabor University. Following the approval, official letter of co-operation was given to the hospital manager. After explanation of the study, a verbal voluntary consent was obtained from each mother. As the study was conducted through face to face interview, the individual participants were not exposed to any physical harm. Moreover, the mothers were told that the information they gave to be treated with complete confidentiality and do not cause any harm. After every interview, each mother was taught about the harmfulness of traditional uvulectomy, its misconceived advantages and availability of modern medicine to treat elongated uvula utributable neonatal illness. Each mother was also provided with a template that contained diagrammatic illustration of the complications of traditional neonatal uvulectomy in local language, Amharic. Moreover, every 
mother was informed of practicing immediate health care seeking to nearby clinic as early as possible after perceiving neonatal illness.

\section{Results}

\section{Socio-demographic characteristics}

All the eligible mothers were participated in the study thereby making $100 \%$ response rate. More than three quarters of the respondent mothers were urban residents [324(76.8\%)] and nearly similar number of respondents [322(76.3\%)] were in the age group of 20-34 years old. Nearly all the mothers [406(96.2\%)] were married. More than half of the mothers were primiparous [223(52.8\%)]. Regarding educational status, about one fifth of the mothers [76(18\%)] and $32(7.6 \%)$ of the husbands were unable to read and write. Moreover, about half of the mothers were civil servants [216(51.2\%)]. More than two third of the respondent mothers [283 (67.1\%)] had an average monthly income above poverty line (Table 1).

\section{Obstetrics related factors}

Four hundred five $(96.0 \%)$ mothers had antenatal care during pregnancy of the index neonate. However, only about two third of them [277(65.6\%)] attended four and above ANC visits. It was about one third of the mothers [125(30.9\%)] who were accompanied with their spouses during antenatal care. Regarding counseling of traditional neonatal uvulectomy, 103 (63.0\%) mothers were given antenatal counseling. Besides, $44(42.7 \%)$ of the mothers were given the counseling together with their husbands. Nearly one third [130(30.8\%)] of the mothers gave birth at home. Moreover, about $80 \%$ of the respondent mothers had at least one post natal care visit and only $46(13.7 \%)$ of whom attended the second postnatal care visit. During postnatal care visit, 317 (94.6\%) respondent mothers were accompanied by their spouses. More than one third of the mothers [127 (37.9\%)] were counseled of traditional neonatal uvulectomy during their post natal care. However, only $48(37.8 \%)$ of them were given the counseling together with their spouses. The counseling was about disadvantages of traditional neonatal uvulectomy $85(66.9 \%)$, presence of modern medicine for perceived neonatal illness attributed to elongated uvula 46 (36.2\%), immediate modern health care seeking behavior during maternal perception of elongated uvula 54 $(42.5 \%)$ and the benefits of uvula $22(17.3 \%)$ (Table 2$)$.

\section{Neonatal characteristics}

About three fifth [251(59.5\%)] of the neonates were females. One fifth of the neonates [87 (20.6\%)] were born before 37 weeks of gestational age. Most of the neonates [254 (60.2\%)] were admitted to the hospital in the first 7 days of their postnatal age. One third of the neonates [140 (33.2\%)] had low birth weight. At admission, neonates had several medical diagnoses of which hypothermia accounted for the highest percentage [295(69.9\%)] followed by early onset [213(50.5\%)] and late onset neonatal sepsis [114(27.0\%)] (Table 3).

\section{Maternal knowledge of neonatal uvula and traditional uvulectomy}


More than three-fourth of the respondent mothers [330 (78.2\%)] didn't mention at least one benefit of neonatal uvula. Furthermore, more than half [230 (54.5\%)] of the respondent mothers didn't mention at least one disadvantage of traditional neonatal uvulectomy. This quantitative finding can be supplemented by the qualitative evidence obtained from 5 key informants who said 'All neonatal care providers in NICU told me that disease condition of my kid was attributed to postuvulectomy infection. However, I strongly disagree with association of my neonatal illness to the procedure of traditional uvulectomy because the neonates' illness occurred one week after uvulectomy. If the illness had been attributed to uvulectomy, the kid could have been ill soon after the procedure.'The authors reached that this indicates their lack of awareness towards the so called incubation period which is between the procedure of traditional uvulectomy and sepsis onset.

There were 94 (22.3\%) respondent mothers with prior exposure of traditional uvulectomy for their neonates (Table 4).

\section{Proportion of traditional neonatal uvulectomy}

There were 67 (15.9\%) neonatal admissions attributed to the complications of traditional uvulectomy (figure 1). Post uvulectomy sepsis [59 (88.1\%)] comprised the highest proportion of these complications. The mean neonatal age at uvulectomy was 5.42 days $(S D= \pm 2.51)$. Majority [ $42(62.7 \%)]$ of the uvulectomies were done before the $7^{\text {th }}$ day of postnatal life (Table 5). Neonates' failure to breast feed 16 $(23.9 \%)$ was the most reported indicator of elongated uvula (figure 2). Regarding reasons of traditional uvulectomy, $53(79.1 \%)$ mothers claimed that elongated uvula can't be treated by modern medicine (Figure 3). Qualitatively, 5 key informants also said: 'When there is elongated uvula, contacting the traditional surgeon is the absolute medicine because, unless so, the elongated uvula becomes ruptured thereby causing inevitable neonatal death. For example, fearing this inevitable death, all my elder children had uvulectomy done during their neonatal lives after which they grew very well. There has been no modern treatment of elongated uvula since earlier times in our society'

\section{Factors associated with traditional neonatal uvulectomy}

From bivariable analysis, sex of the neonate, parity, place of delivery, antenatal couple counseling of traditional neonatal uvulectomy, postnatal couple counseling of traditional neonatal uvulectomy, mentioning at least one disadvantage of traditional neonatal uvulectomy, having history of traditional neonatal uvulectomy and history of bad obstetrics were significant factors. However, after adjusting for possible confounding effect in multivariable analysis, sex of the neonate [AOR=4.87; 95\% Cl: 1.10, 21.59], antenatal couple counseling of traditional neonatal uvulectomy [AOR=0.053; $95 \% \mathrm{Cl}: 0.01,0.35$ ], home delivery [AOR $=6.02 ; 95 \% \mathrm{Cl}: 1.15,31.61]$, postnatal couple counseling of traditional neonatal uvulectomy [AOR $=0.101 ; 95 \% \mathrm{Cl}: 0.02,0.65]$, having history of traditional neonatal uvulectomy [AOR= $7.15 ; 95 \% \mathrm{Cl}$ : $1.18,43.21]$ and mentioning at least one disadvantage of traditional neonatal uvulectomy [AOR=0.068; $95 \% \mathrm{Cl}: 0.01,0.44]$ were independent predictors of the malpractice. 
The odds of traditional uvulectomy among male neonates were 4.87 times higher as compared to female neonates [AOR $=4.87 ; 95 \% \mathrm{Cl}: 1.10,21.59]$. Neonates born to parents who were couple counseled of traditional neonatal uvulectomy during antenatal period were $94.7 \%$ less likely to be victim as compared to those neonates born to parents who weren't couple counseled [AOR=0.053; 95\% $\mathrm{Cl}: 0.01,0.35$ ].

Home delivered neonates were 6.02 times more likely to have traditional uvulectomy when compared to those born at health institution [AOR $=6.02 ; 95 \% \mathrm{Cl}: 1.15,31.61]$. It was supported by the qualitative data of 4 key informants who said: 'After I delivered at home, all the men and women who helped me during the birth were dealing with the essence of contacting traditional uvulectomy practitioners if my kid becomes irritable despite good breastfeeding. This is because nowadays elongated uvula is chiefly characterized by irritability rather than decreased breastfeeding. Then, I experienced traditional uvulectomy when I was in trouble of the kid's spontaneous crying despite its successful breastfeeding'

Moreover, neonates born to mothers with prior history of traditional neonatal uvulectomy were 7.15 times more likely to experience the malpractice as compared to those without the history $[\mathrm{AOR}=7.15 ; 95 \% \mathrm{Cl}$ : $1.18,43.21]$. The likelihood of traditional uvulectomy among neonates whose mothers and fathers recieved counseling of traditional uvulectomy during postnatal visit was $89.9 \%$ lower than those whose parents weren't couple counseled [AOR $=0.101 ; 95 \% \mathrm{Cl}: 0.02,0.65]$. This finding was supported by a key informant who said: 'Just in front of our kid at post natal room, my husband and me were advised of the life threatening septic and hemorrhagic complications of traditional neonatal uvulectomy which we had never known before. It was heart touching to hear the advice in front of our kid. Since then, we promised never to experience traditional uvulectomy for our kid'.

Neonates whose mothers mentioned at least one disadvantage of traditional neonatal uvulectomy were 93.2\% less likely to be victim when compared to those whose mothers mentioned none [AOR= $0.068 ; 95 \%$ Cl: $0.01,0.44]$ (Table 6). This is supported by the qualitative data obtained from 3 key informants who said: 'I observed when my neighbor's neonate was done uvulectomy. Some days after the procedure, the neonate developed severe illness manifested by intermittent vomiting of bloody content and strangely difficult type of breathing. Just at that time, the parents and me were too much worried of the neonate's condition and hence we contacted the traditional practitioner who did the procedure, but he himself was very disturbed when he saw the neonate was vomiting blood. Ultimately, expecting no more solution from the practitioner, we left him and brought the neonate to this hospital. The neonate got cured after it was oxygenated, given medications and blood transfused. The neonatal care providers told us that the neonate suffered from blood loss from hemorrhage during the procedure and also infection. Then, we became convinced and decided never to face traditional neonatal uvulectomy in our village again. The traditional practitioners receive 200 ETB (Ethiopian Birr) per neonate thereby considering the malpractice as their source of income. They should be asked by law because they are endangering neonatal health by encouraging parents for uvulectomy rather than advising for modern medicine here at hospital.

\section{Discussion}


This study tried to address public health importance of traditional neonatal uvulectomy in showing its burden, associated factors and reasons in the study area. Proportion of postuvulectomy admission was $15.9 \%$. Male sex, home delivery and prior history of traditional uvulectomy were significantly associated with increased odds of traditional neonatal uvulectomy whereas knowing at least one disadvantage of traditional uvulectomy, antenatal and postnatal couple counseling about traditional uvulectomy was significantly associated with decreased odds of the malpractice.

From this study, the proportion of traditional uvulectomy (15.9\%) was consistent with the proportion of the malpractice in Niger (19.6) [19]. However, it was lower than studies in Aksum (86.9\%) [18] and Nigeria (86.1\%) [28] but higher than a Tanzanian study (1.0\%) [11].This discrepancy may be due to differences in study setting, period, design and target population.

The odds of traditional uvulectomy among male neonates were 4.87 times higher as compared to female neonates. This may be due to the fact that in the study area male sex is preferred and considered as a pride in the community. Thus, special traditional cares like traditional uvulectomy and prelacteal feeding are given whenever there is any sign of perceived neonatal illness [29]. However, according to a cross sectional study among outpatient children at a district hospital in Kenya, there was no significant disparity of traditional uvulectomy in childhood sex [8].

Neonates born to parents who were couple counseled of traditional neonatal uvulectomy in the antenatal and postnatal periods were $94.7 \%$ and $89.9 \%$ less likely to be victim of the malpractice respectively as compared to those born to only whose mothers counseled of the malpractice. This could be due to the fact that couple counseling helps parents to have couple understanding towards the natural benefits of uvula, the disadvantages of traditional uvulectomy and presence of modern medicine. Furthermore, postnatatal couple counseling is the most crucial event during which the parents can be convinced of their misconception about severity of the malpractice in front of their neonates. Therefore, the couple can then prefer the modern health care to traditional uvulectomy during their perception of elongated uvula attributable neonatal illness $[12,30]$.

The odds of traditional uvulectomy among home delivered neonates were 6.02 times higher as compared to those born at health institution. This could be due to the fact that, in Ethiopia, mothers who gave their birth at home don't usually attend postnatal care [30]. Therefore, these mothers don't get postnatal couple counseling of traditional uvulectomy, which is a significant determinant of the malpractice as to this study. Moreover, traditional birth attendants whose advice accepted in the community are thought to play their roles in encouraging traditional uvulectomy $[8,12,18,19,21]$.

Moreover, neonates born to mothers with prior history of traditional neonatal uvulectomy were 7.15 times more likely to experience the malpractice as compared to those without the history. This may be due to the deeply rooted cultural advocacy of the malpractice in the community to heal parental perception of elongated uvula before its rupture to treat their misconceived inevitable neonatal death at time of rupture $[1,4,7,8,11,18,19]$. 
Neonates whose mothers knew at least one disadvantage of traditional neonatal uvulectomy were $93.2 \%$ less likely to be victim when compared to those whose mothers don't know any of the disadvantages. This could be due to the fact that if a mother is knowledgeable of the disadvantages, she becomes reserved of the malpractice to prevent her neonatal suffering [8]. Therefore, continuous training and retraining of community agents about the dangerous disadvantages (complications) of traditional neonatal uvulectomy should be instituted in the health care system of the study area.

In the developed world, uvulectomy is done as part of a combined procedure of uvulopalatopharyngoplasty, to ameliorate conditions like snoring [31]. However, there is not a mention in the literature from different parts of the world about traditional uvulectomy on account of its indications. Despite this, maternal perception of 'no modern medicine to treat elongated uvula was the most mentioned reason of traditional uvulectomy for which traditional practitioners were contacted to prevent rupture of elongated uvula, perceived as fatal.

Majority [42 (62.7\%)] of the traditional uvulectomies were performed before the $7^{\text {th }}$ day of life, which is similar with a Nigerian study [26] showing $52.4 \%$ of the uvulectomies performed within 7 days of postnatal life. Literature shows the first 7 days of postnatal life is a critical time during which significant early neonatal death has been reported from across the globe, mainly in developing countries $[9,12,25$, $30,32]$.Thus, during this period, undergoing traditional uvulectomy and other cultural malpractices has public health importance. This in turn necessitates exhaustive investment of different programmatic interventions on the avoidance of these malpractices to save early neonatal lives.

Post uvulectomy sepsis [59 (88.1\%)] was the leading complication that victim neonates had at admission owing to probably the use of unsterilized instruments on several neonates on the same session as stated by the key informants of this study. Most importantly, sepsis can be ensued by septicemia which is fatal $[4,6,8,12,26,28]$. Therefore, preventive interventions like educating the community about case fatality of septic complication of uvulectomy should be targeted and exhaustively done.

\section{Limitation of the study}

It was a single center study limited to neonates admitted to Debre Tabor General Hospital alone and hence couldn't reflect the burden of traditional neonatal uvulectomy in the study area. Therefore, the authors recommend a multicenter cohort study to show wider picture of the malpractice and its treatment outcome in the health care system.

\section{Conclusions And Recommendations}

The burden of traditional neonatal uvulectomy was high. Fortunately, its predictors namely sex of the neonate, antenatal and postnatal couple counseling of traditional neonatal uvulectomy, home delivery, history of traditional neonatal uvulectomy and knowledge of the disadvantages of traditional neonatal uvulectomy are modifiable. Therefore, strong advocacy teams of neonatal health should be organized from the lowest administrative level (Gotes) to the highest level (Zone) to mobilize the community 
against the malpractice. The advocacy team should involve different community groups like women health development armies, elders, religious fathers, health extension workers and health professionals. Moreover, criminal prosecutors should be engaged in the team to get legal concern of traditional neonatal uvulectomy as it elicits unnecessary complications that endanger neonatal lives. These advocacy teams should be strengthened and supported one another through their hierarchal referral linkages i.e (Gote $\leftrightarrow$ Kebele $\leftrightarrow$ Woreda $\leftrightarrow$ Zone).

The key message of 'no traditional neonatal uvulectomy' should be integrated and properly implemented in the routine antenatal and postnatal programs of the health care delivery system at South Gondar zone to promote parental couple counseling about harmfulness of the malpractice. Maternal and neonatal health care providers should also advocate the legal and public health interventions of eliminating this dangerous practice. Besides, designing strategies to enhance community health care seeking behavior during parental suspicion of neonatal illness attributed to elongated uvula is another important method of preventing the malpractice.

\section{Abbreviations}

CSA: Central Statistical Agency; DTGH: Debre Tabor General Hospital; DTU: Debre Tabor University; EDHS: Ethiopian Demographic Health Survey; NICU: Neonatal Intensive care unit

\section{Declarations}

\section{Ethical approval and consent to participate}

Ethical approval with ethics approval number of DTU-CHS-013 was obtained from Debre Tabor University, College of Health Sciences, Institutional Health Research Ethics Review Committee (IHRERC). An informed verbal voluntary consent was obtained from all the eligible mothers. Mothers preferred oral consent because it was a study that they themselves were interested to contribute for the beneficent sake of neonatal health after securing the nonmalficent and confidentiality issues orally as stated in the participant information sheet. Moreover, all eligible mother newborn dyads were further ethically secured by the written, voluntary and signed consent that the authors already made with the hospital ethical review board before the start up of data collection.

Consent to publication: Not applicable

Availability of data and materials. Data will be available upon request from the corresponding author.

Competing interests. The authors declare that they have no competing interests.

Funding. This research didn't receive any grant from any funding agency in the public, commercial or notfor-profit sectors. 
Authors' Contribution:WA, the corresponding author, worked on designing the study, training and supervising the data collectors, interpreting the result and preparing the manuscript. The co-authors namely BM, AY and DM played their roles in analyzing and interpreting the result. All authors were involved in writing, reading and approving of the final manuscript.

Acknowledgment: The author acknowledged the director of Debre Tabor General Hospital, data collectors, supervisors and data entry operators. The author is also deeply indebted to the Institutional Health Research Ethics Review Committee (IHRERC) of Debre Tabor University for working on the ethical perspectives of the proposal and letting do this study. Last but not least, the respondents deserve the authors' sincerest thanks for their kind responses.

\section{References}

1. Gabriel Toye Olajide et al./ International Journal of Medical Reviews and Case Reports: traditional uvulectomy: origin, perception, burden and strategies of prevention

2. Uvula Removal Surgery And Side Effects: Functions Of Uvula Published November 16, 2010 by PUP http://www.tandurust.com/health-faq-5/uvularemoval-surgery-effects.html

3. Harmful Traditional Practices for the Ethiopian Health Center Team. EPHI, 2005.

4. Parental Reasons and Perception of Traditional Uvulectomy In Children. Sahel Medical Journal, Vol. 14 No.4, October - December, 2011 (210 - 216)

5. Naidoo and Agbor., Afr J Tradit Complement Altern Med. (2016) 13(2):133-142: http://dx.doi.org/10.4314/ajtcam.v13i2.16

6. Mboneko and F. Fabian, "Traditional uvulectomy and reported complications in under-five children in Mkuranga district Pwani region, Eastern Tanzania," Tanzania Dental Journal, vol. 12, no. 2, pp. 6569, 2006.

7. Owibingire SS, Kamya ER, Sohal KS. Beliefs about Traditional Uvulectomy : Awareness and Perception among Adults in Tanzanian Rural Setting. Ann. Int. Med. Den. Res. 2018; 4(2): DE25DE30.

8. Determinants of the practice of traditional uvulectomy as seen at Thika District Hospital: A survey on children below five years, 2005.

9. CSA AND ICF 2016. Ethiopian Demographic and Health Survey 2016. https://dhsprogram.com/pubs/pdf/FR328/FR328.pdf.

10. Debre Tabor General Hospital. Neonatal admission registration book, 2015-2018.

11. R. Sawe, et al. 2015. Morbidity and Mortality following Traditional Uvulectomy among Children Presenting to the Muhimbili National Hospital Emergency Department in Dar es Salaam, Tanzania

12. National Strategy and Action Plan on Harmful Traditional Practices (HTPs) against Women and Children in Ethiopia Federal Democratic Republic of Ethiopia Ministry of Women, Children and Youth Affairs (MoWCYA) June, 2013 Addis Ababa 
13. Plan international and WHO: Protecting children from harmful practices in plural legal systems with a special emphasis on Africa. New York: 2012.

14. EGLDAM, Follow up National Survey on Harmful Traditional Practices in Ethiopia, 2008.

15. Dawit, W. Eshetu, G. Masresha, B. Misganaw, and M. Atsinaf, Harmful Traditional Practices: Module for Ethiopian Health Center Team, Ethiopian Public Health Training Institute.

16. Awassa College, 2004, Harmful Traditional Practices: Module for Ethiopian Health Center Team, Ethiopian Public Health Training Institute.

17. UNCHR, Harmful Traditional Practices Affecting the Health of Women and Children, Fact Sheet No. 23, UN Office of the High Commissioner for Human Rights (UNCHR), Geneva, Switzerland, 2006.

18. Gebrekirstos et al.: A cross sectional study on factors associated with harmful traditional practices among children less than 5 years in Axum town, north Ethiopia, 2013. Reproductive Health 2014 $11: 46$

19. Traditional uvulectomy among children in Niger, a public health problem? Journal of Elseveir Science direct

20. Asefa, E. Wassie, M. Getahun, M. Berehaneselassie, and A. Melaku, Harm Full Traditional Practices for the Ethiopian Health Center Team, Ethiopian public health training initiative (EPHTI) manual, Awasa College, 2005, Harm full traditional practices for the Ethiopian health center team. Ethiopian public health training initiative (EPHTI) manual, Awasa College.

21. Hailu Z, Nishan B, Adissu A: Assessment and Strategic Intervention to Combat Harmful Traditional Practices/HTPs/ in Benishangul Gumuz Region, Final report. Assosa: 2011.

22. NCTPE: Baseline survey on harmful traditional practices in Ethiopia. Addis Ababa: 1998.

23. African Union: PAN-AFRICAN conference on celebrating courage and overcoming harmful traditional practices in Africa report. Addis Ababa, Ethiopia: AU conference centre; 2011.

24. Getu Degu A, Melkie E: Knowledge, Attitudes and Practices involved in Harmful Health Behavior in Dembia District, northwest Ethiopia. Ethiop J Health Dev 2002, 16(2):199-207.

25. South Gondar Zone Health Department, 2018

26. Abdullahi M, Amutta SB. Traditional Uvulectomy Among The Neonates: Experience In A Nigerian Tertiary Health Institution Bo Med J 2016; 13(1):16 - 20.

27. Suheyla and V. Katabi, "Comparison of Cultural Practices Used in Pregnancy Postpartum Periods among Women in Turkey \& Iran," 2008. WHO, WHO Regional Health Forum South-East Asia Region, vol. 6, World health organization (WHO), 2008.

28. Adeyi A. et al. 2011. The Traditionally Amputate Uvula amongst Nigerians: Still an Ongoing Practice

29. Gualu et al. 2017. Determinants of prelacteal feeding practice among postpartum mothers in Debre Markos town, Amhara regional state, Ethiopia, 2016, Volume 9: DO - 10.2147/NDS.S146188, Nutrition and Dietary Supplements

30. BASIC EMERGENCY OBSTETRIC \& NEWBORN CARE (BEmONC) Training Manual Federal Democratic Republic of Ethiopia, Ministry of Health, 2018. 
31. Ariyasu, G. Young, and F. Spinelli, "Uvulectomy in the office setting," Ear, Nose and Throat Journal, vol. 74, no. 10, pp. 721- 722, 1995.

32. UNICEF, WHO, Bank W, Division U-DP. Levels \& Trends in Child Mortality: Estimates Developed by UN Inter-agency Group the for Child Mortality Estimation. 2017.

\section{Tables}

Table 1: Socio-demographic and reproductive characteristics among postnatal mothers whose neonates admitted to Neonatal Intensive Care Unit of Debre Tabor General Hospital, Debre Tabor town, North Central Ethiopia, 2019 (n=422).

\begin{tabular}{|c|c|c|}
\hline Factor & $\mathrm{N}$ & $\%$ \\
\hline \multicolumn{3}{|l|}{ Residence } \\
\hline Urban & 324 & 76.8 \\
\hline Rural & 98 & 23.2 \\
\hline \multicolumn{3}{|l|}{ Maternal age (years) } \\
\hline$<20$ & 29 & 6.9 \\
\hline $20-34$ & 322 & 76.3 \\
\hline$\geq 34$ & 71 & 16.8 \\
\hline \multicolumn{3}{|l|}{ Marital status } \\
\hline Married & 406 & 96.2 \\
\hline Other* & 16 & 3.8 \\
\hline \multicolumn{3}{|l|}{ Parity } \\
\hline Primiparous & 223 & 52.8 \\
\hline Multiparous & 199 & 47.2 \\
\hline \multicolumn{3}{|l|}{ Maternal educational status } \\
\hline Unable to read and write & 76 & 18.0 \\
\hline Primary education & 202 & 47.9 \\
\hline Secondary education & 82 & 19.4 \\
\hline College/university & 62 & 14.7 \\
\hline \multicolumn{3}{|l|}{ Husband's educational status } \\
\hline Unable to read and write & 32 & 7.6 \\
\hline Primary education & 127 & 30.1 \\
\hline Secondary education & 148 & 35.1 \\
\hline Secondary education & 115 & 27.3 \\
\hline \multicolumn{3}{|l|}{ Maternal occupation } \\
\hline Civil servant & 216 & 51.2 \\
\hline Merchant & 119 & 28.2 \\
\hline House wife & 87 & 20.6 \\
\hline \multicolumn{3}{|l|}{ Average monthly income (\$ US) } \\
\hline$<37.5$ & 139 & 32.9 \\
\hline$\geq 37.5$ & 283 & 67.1 \\
\hline
\end{tabular}

* Other refers to divorced, widowed 
Table 2: Obstetrics related factors among postnatal mothers whose neonates admitted at Neonatal Intensive Care Unit of Debre Tabor General Hospital, Debre Tabor town, North Central Ethiopia, 2019. 


\begin{tabular}{|c|c|c|}
\hline Factor & $\mathrm{n}$ & $\%$ \\
\hline \multicolumn{3}{|l|}{ ANC follow up (n=422) } \\
\hline Yes & 405 & 96.0 \\
\hline No & 17 & 4.0 \\
\hline \multicolumn{3}{|l|}{ Number of ANC visits $(n=405)$} \\
\hline$<4$ times & 128 & 30.3 \\
\hline$\geq 4$ times & 277 & 65.6 \\
\hline \multicolumn{3}{|l|}{ Accompanied by spouse to ANC $(n=405)$} \\
\hline Yes & 125 & 30.9 \\
\hline No & 280 & 69.1 \\
\hline \multicolumn{3}{|l|}{ Antenatal counseling of traditional neonatal uvulectomy $(n=405)$} \\
\hline Yes & 103 & 63.0 \\
\hline No & 302 & 32.9 \\
\hline \multicolumn{3}{|l|}{ Antenatal couple counseling of traditional neonatal uvulectomy $(\mathrm{n}=103)$} \\
\hline Yes & 44 & 42.7 \\
\hline No & 59 & 57.3 \\
\hline \multicolumn{3}{|l|}{ *What were you counseled? $(\mathrm{n}=103)$} \\
\hline Disadvantages of traditional neonatal uvulectomy & 57 & 55.3 \\
\hline $\begin{array}{l}\text { Immediate modern health care seeking during perception of elongated } \\
\text { uvula }\end{array}$ & 46 & 44.7 \\
\hline The presence of modern medicine for elongated uvula & 33 & 32.0 \\
\hline Benefits of uvula & 16 & 15.5 \\
\hline \multicolumn{3}{|l|}{ Ever had bad obstetrics history $(n=422)$} \\
\hline Yes & 75 & 17.8 \\
\hline No & 347 & 82.2 \\
\hline \multicolumn{3}{|l|}{ *If yes, which of the following? $(n=75)$} \\
\hline Neonatal death & 48 & 64.0 \\
\hline Child death & 35 & 46.7 \\
\hline Still birth & 32 & 42.7 \\
\hline Abortion & 17 & 22.7 \\
\hline IUFD & 9 & 12.0 \\
\hline \multicolumn{3}{|l|}{ Place of delivery $(\mathrm{n}=422)$} \\
\hline Health institution & 286 & 67.8 \\
\hline Home & 136 & 32.2 \\
\hline \multicolumn{3}{|l|}{ PNC visit $(n=422)$} \\
\hline Yes & 335 & 79.4 \\
\hline No & 87 & 20.6 \\
\hline \multicolumn{3}{|l|}{${ }^{*}$ Number of PNC visits $(n=335)$} \\
\hline $1^{\text {st }}$ PNC visit (Within 24 hours of birth) & 304 & 90.7 \\
\hline $2^{\text {nd }}$ PNC visit $(1-7)$ days after birth & 46 & 13.7 \\
\hline \multicolumn{3}{|l|}{ Accompanied by spouse to PNC $(n=335)$} \\
\hline Yes & 317 & 94.6 \\
\hline
\end{tabular}




\begin{tabular}{|l|l|l|} 
No & 18 & 5.4 \\
\hline Postnatal counseling about traditional neonatal uvulectomy(n=335) & & \\
\hline Yes & 127 & 37.9 \\
\hline No & 208 & 62.1 \\
\hline Postnatal couple counseling about traditional neonatal uvulectomy (n=127) & & \\
\hline Yes & 48 & 37.8 \\
\hline No & 79 & 62.2 \\
\hline *What were you counseled (n=127) & & \\
\hline Disadvantages of traditional neonatal uvulectomy & 85 & 66.9 \\
\hline $\begin{array}{l}\text { Immediate modern health care seeking during perception of elongated } \\
\text { uvula }\end{array}$ & 54 & 42.5 \\
\hline The presence of modern medicine for elongated uvula & & \\
\hline Benefits of uvula & 46 & 36.2 \\
\hline
\end{tabular}

*Multiple responses were given

NB: the third PNC visit wasn't considered as neonates are younger than this visit time.

Table 3: Characteristics of the neonates admitted at Neonatal Intensive Care Unit of Debre Tabor General Hospital, Debre Tabor town, North Central Ethiopia, 2019.

\begin{tabular}{|l|l|l|l|}
\hline Variable (n=422) & Category & $\mathrm{N}$ & $\%$ \\
\hline \multirow{3}{*}{ Sex } & Male & 171 & 40.5 \\
\cline { 2 - 4 } & Female & 251 & 59.5 \\
\hline Gestational age at birth & $<37$ weeks & 87 & 20.6 \\
\cline { 2 - 4 } & $\geq 37$ weeks & 335 & 79.4 \\
\hline Post natal age at admission (days) & $<7$ & 254 & 60.2 \\
\cline { 2 - 4 } & $\geq 7$ & 168 & 39.8 \\
\hline Birth weight (grams) & $<2500$ & 140 & 33.2 \\
\cline { 2 - 4 } & $\geq 2500$ & 282 & 66.9 \\
\hline \multirow{3}{*}{ Medical diagnosis @ admission } & Hypothermia & 295 & 69.9 \\
\cline { 2 - 4 } & Early onset neonatal sepsis & 213 & 50.5 \\
\cline { 2 - 4 } & Late onset neonatal sepsis & 114 & 27.0 \\
\cline { 2 - 4 } & Prematurity & 87 & 20.6 \\
\cline { 2 - 4 } & Perinatal asphyxia & 75 & 17.8 \\
\cline { 2 - 4 } & Hypoglycemia & 62 & 14.7 \\
\cline { 2 - 4 } & Congenital defect & 58 & 13.7 \\
\hline
\end{tabular}

*refers to the presence of multiple medical diagnoses for a neonate at admission 
Table 4: Knowledge of neonatal uvula and traditional uvulectomy among postnatal mothers whose neonates admitted at Neonatal Intensive Care Unit of Debre Tabor General Hospital, Debre Tabor town, North Central Ethiopia, 2019.

\begin{tabular}{|c|c|c|c|}
\hline Factor & Response & $\mathbf{N}$ & $\%$ \\
\hline \multirow{2}{*}{$\begin{array}{l}\text { Mentioned at least one benefit of uvula } \\
(\mathrm{n}=422)\end{array}$} & Yes & 92 & 21.8 \\
\hline & No & 330 & 78.2 \\
\hline \multirow[t]{5}{*}{${ }^{*}$ The mentioned benefits of uvula $(n=92)$} & $\begin{array}{l}\text { Preventing aspiration while } \\
\text { swallowing breast milk }\end{array}$ & 77 & 83.7 \\
\hline & Lubricating oropharyngeal mucosa & 18 & 19.6 \\
\hline & $\begin{array}{l}\text { Serving for language } \\
\text { communication }\end{array}$ & 15 & 16.3 \\
\hline & Boosting immunological function & 12 & 13.0 \\
\hline & $\begin{array}{l}\text { prevention of breast milk } \\
\text { regurgitation through the neonatal } \\
\text { nose }\end{array}$ & 9 & 9.8 \\
\hline \multirow{2}{*}{$\begin{array}{l}\text { Mentioned at least one disadvantage of } \\
\text { traditional neonatal uvulectomy }(\mathrm{n}=422)\end{array}$} & Yes & 192 & 45.5 \\
\hline & No & 230 & 54.5 \\
\hline \multirow[t]{10}{*}{$\begin{array}{l}{ }^{*} \text { The mentioned disadvantages of } \\
\text { traditional neonatal uvulectomy }(\mathrm{n}=192)\end{array}$} & $\begin{array}{l}\text { Transmission of communicable } \\
\text { infections (HIV, Hep B) }\end{array}$ & 146 & 76.0 \\
\hline & Hemorrhage & 51 & 26.6 \\
\hline & Tetanus & 39 & 20.3 \\
\hline & Pharyngeal dryness & 25 & 13.0 \\
\hline & Aspiration & 17 & 8.9 \\
\hline & Pain & 10 & 5.2 \\
\hline & Change in voice & 9 & 4.7 \\
\hline & disturbance in sleep pattern & 7 & 3.6 \\
\hline & $\begin{array}{l}\text { Regurgitation of breast milk from } \\
\text { the nostril }\end{array}$ & 7 & 3.6 \\
\hline & Others & 9 & 4.7 \\
\hline \multirow{2}{*}{$\begin{array}{l}\text { Prior history of traditional neonatal } \\
\text { uvulectomy }(\mathrm{n}=\mathbf{4 2 2})\end{array}$} & Yes & 94 & 22.3 \\
\hline & No & 328 & 77.7 \\
\hline
\end{tabular}

* Multiple responses were given; others refer to tongue injury and neck swelling

Table 5: Characteristics of victim neonates of traditional uvulectomy among admissions to NICU at Debre Tabor General Hospital, North Central Ethiopia, 2019. 


\begin{tabular}{|c|c|c|c|}
\hline Factor & Response & $\mathrm{n}$ & $\%$ \\
\hline \multirow[t]{2}{*}{ Neonatal age at uvulectomy $(\mathrm{n}=67)$} & $<7$ days & 42 & 62.7 \\
\hline & $\geq 7$ days & 25 & 37.3 \\
\hline \multirow[t]{5}{*}{$\begin{array}{l}\text { *Who did influence you to practice traditional } \\
\text { neonatal uvulectomy? }(\mathrm{n}=67)\end{array}$} & $\begin{array}{l}\text { Traditional uvulectomy } \\
\text { practitioners }\end{array}$ & 27 & 40.3 \\
\hline & Family & 23 & 34.3 \\
\hline & $\begin{array}{l}\text { Traditional birth } \\
\text { attendants }\end{array}$ & 19 & 28.4 \\
\hline & Friends & 14 & 20.9 \\
\hline & Maternal own decision & 9 & 13.4 \\
\hline \multirow{5}{*}{$\begin{array}{l}\text { What was the primary postuvulectomy complication at } \\
\text { admission? }(\mathrm{n}=67)\end{array}$} & Sepsis & 59 & 88.1 \\
\hline & Anemia & 37 & 55.2 \\
\hline & Neck swelling & 11 & 16.4 \\
\hline & $\begin{array}{l}\text { Tongue and } \\
\text { oropharyngeal injury }\end{array}$ & 7 & 10.4 \\
\hline & Others ${ }^{*}$ & 3 & 4.5 \\
\hline
\end{tabular}

Table 6: Factors associated with traditional uvulectomy among neonatal admissions at Neonatal Intensive Care Unit of Debre Tabor General Hospital, North Central Ethiopia, $2019(n=)$. 


\begin{tabular}{|c|c|c|c|c|}
\hline \multirow[t]{2}{*}{ Factor } & \multicolumn{2}{|c|}{$\begin{array}{l}\text { Traditional neonatal } \\
\text { uvulectomy practice }\end{array}$} & \multicolumn{2}{|l|}{$95 \% \mathrm{CI}$} \\
\hline & Yes & No & Crude OR & $\begin{array}{l}\text { Adjusted } \\
\text { OR }\end{array}$ \\
\hline \multicolumn{5}{|c|}{ Sex of the neonate $(n=422)$} \\
\hline Male & $57(13.50 \%)$ & $114(27.01 \%)$ & $12.10(5.94,24.46)$ & $\begin{array}{l}4.87(1.10 \\
21.59)^{*}\end{array}$ \\
\hline Female & 10 (2.37\%) & $241(57.11 \%)$ & 1 & 1 \\
\hline \multicolumn{5}{|l|}{ Parity $(n=422)$} \\
\hline Primiparous & $45(10.66 \%)$ & $178(42.18 \%)$ & $2.03(1.17,3.53)$ & $\begin{array}{l}\text { 1.42(.27, } \\
7.37)\end{array}$ \\
\hline Multiparous & $22(5.21 \%)$ & $177(41.94 \%)$ & 1 & 1 \\
\hline \multicolumn{5}{|c|}{$\begin{array}{l}\text { Antenatal couple counseling of traditional } \\
\text { uvulectomy }(\mathrm{n}=103)\end{array}$} \\
\hline Yes & $12(11.65 \%)$ & $32(31.07 \%)$ & $.030(.016, .060)$ & $\begin{array}{l}.053(.01 \\
.35)^{* *}\end{array}$ \\
\hline No & $55(53.40 \%)$ & $4(3.88 \%)$ & 1 & 1 \\
\hline \multicolumn{5}{|l|}{ Delivery place $(n=422)$} \\
\hline Home & 58 (13.74\%) & 78 (18.48\%) & $8.41(4.68,15.11)$ & $\begin{array}{l}6.02 \\
(1.15 \\
31.61)^{*}\end{array}$ \\
\hline Health institution & $9(2.13 \%)$ & 277 (65.64\%) & 1 & 1 \\
\hline \multicolumn{5}{|c|}{$\begin{array}{l}\text { Postnatal couple counseling of } \\
\text { traditional uvulectomy }(\mathrm{n}=127)\end{array}$} \\
\hline Yes & 8 (6.30\%) & $40(31.50 \%)$ & $.027(.012, .06)$ & $\begin{array}{l}.101(.02, \\
.65)^{*}\end{array}$ \\
\hline No & $59(46.46 \%)$ & $20(15.75 \%)$ & 1 & 1 \\
\hline \multicolumn{5}{|c|}{$\begin{array}{l}\text { Knowing at least one disadvantage of } \\
\text { traditional uvulectomy }(n=422)\end{array}$} \\
\hline Yes & $4(0.95 \%)$ & 188(44.55\%) & $.056(.02, .16)$ & $\begin{array}{l}.068(.01 \\
.44)^{* *}\end{array}$ \\
\hline No & 63 (14.93\%) & 167(39.57\%) & 1 & 1 \\
\hline \multicolumn{5}{|c|}{$\begin{array}{l}\text { Having history of traditional } \\
\text { uvulectomy }(\mathrm{n}=422)\end{array}$} \\
\hline Yes & $59(13.98 \%)$ & $35(8.29 \%)$ & $51.79(24.29,110.43)$ & $\begin{array}{l}\text { 7.15(1.18, } \\
43.21) *\end{array}$ \\
\hline No & $10(2.37 \%)$ & 318 (75.36\%) & 1 & 1 \\
\hline \multicolumn{5}{|c|}{ History of bad obstetrics $(n=422)$} \\
\hline Yes & $6(1.42 \%)$ & $69(16.35 \%)$ & $.12(.065, .208)$ & $\begin{array}{l}.23(.037 \\
1.423)\end{array}$ \\
\hline No & $61(14.45 \%)$ & 286 (67.77\%) & 1 & 1 \\
\hline
\end{tabular}

$*$ Significant at $<0.03, * *$ significant at $\leq 0.01$ and $* * *$ significant at $\leq 0.001$ 


\section{Figures}

\section{Traditional neonatal uvulectomy}

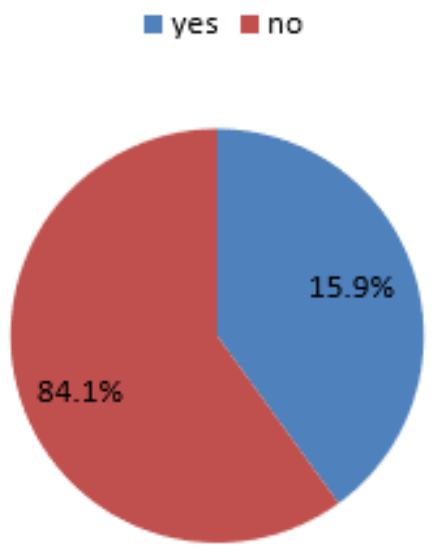

\section{Figure 1}

Proportion of postuvulectomy admissions at Neonatal Intensive Care Unit of Debre Tabor General Hospital, 2019.

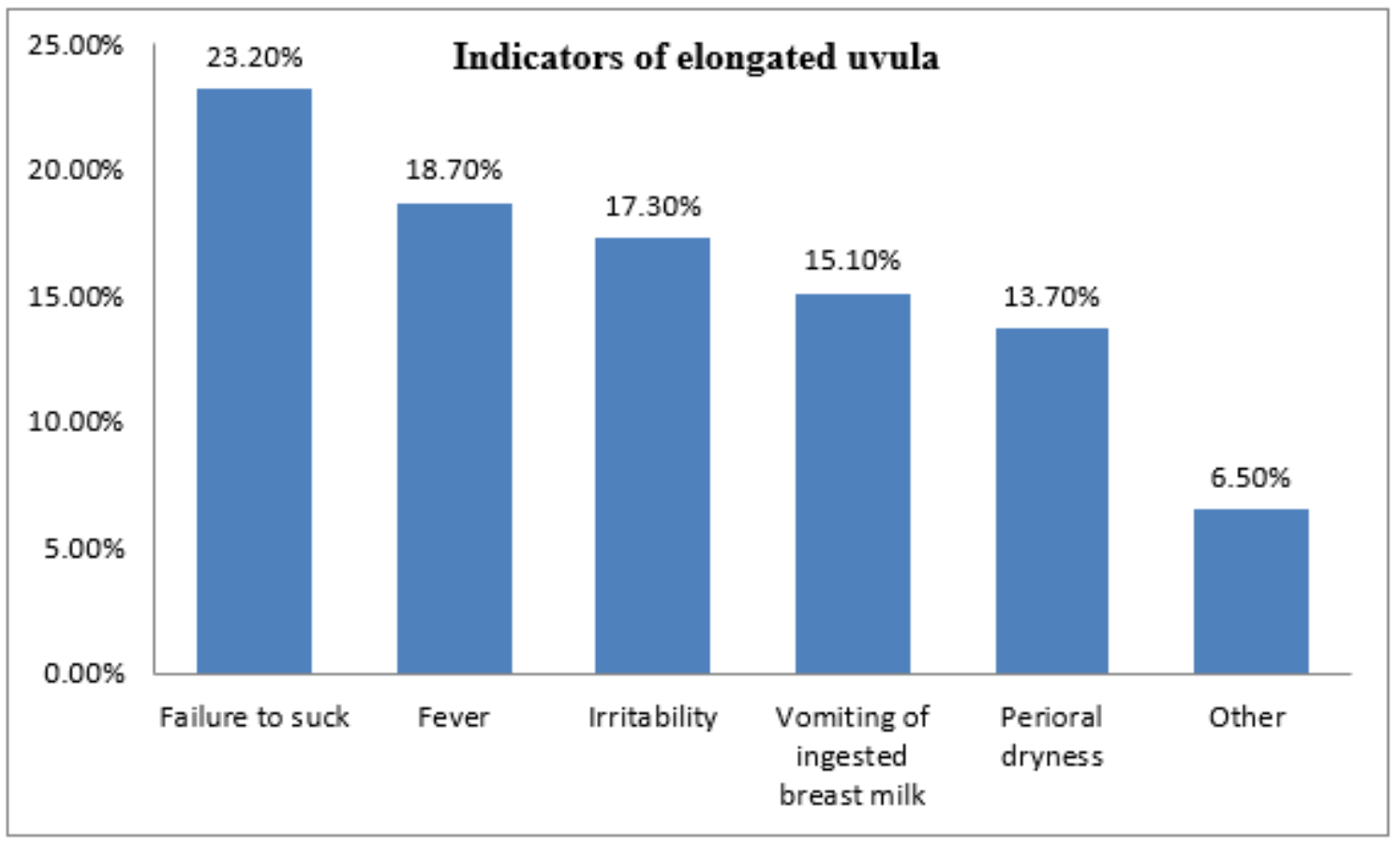

Other refers to "cough, skin rash, fontanel bulge, diarrhea and too sleepy neonates

\section{Figure 2}

Indicators of elongated uvula as to postnatal mothers of the admitted neonates, Debre Tabor General Hospital, South Gondar Zone, 2019. 


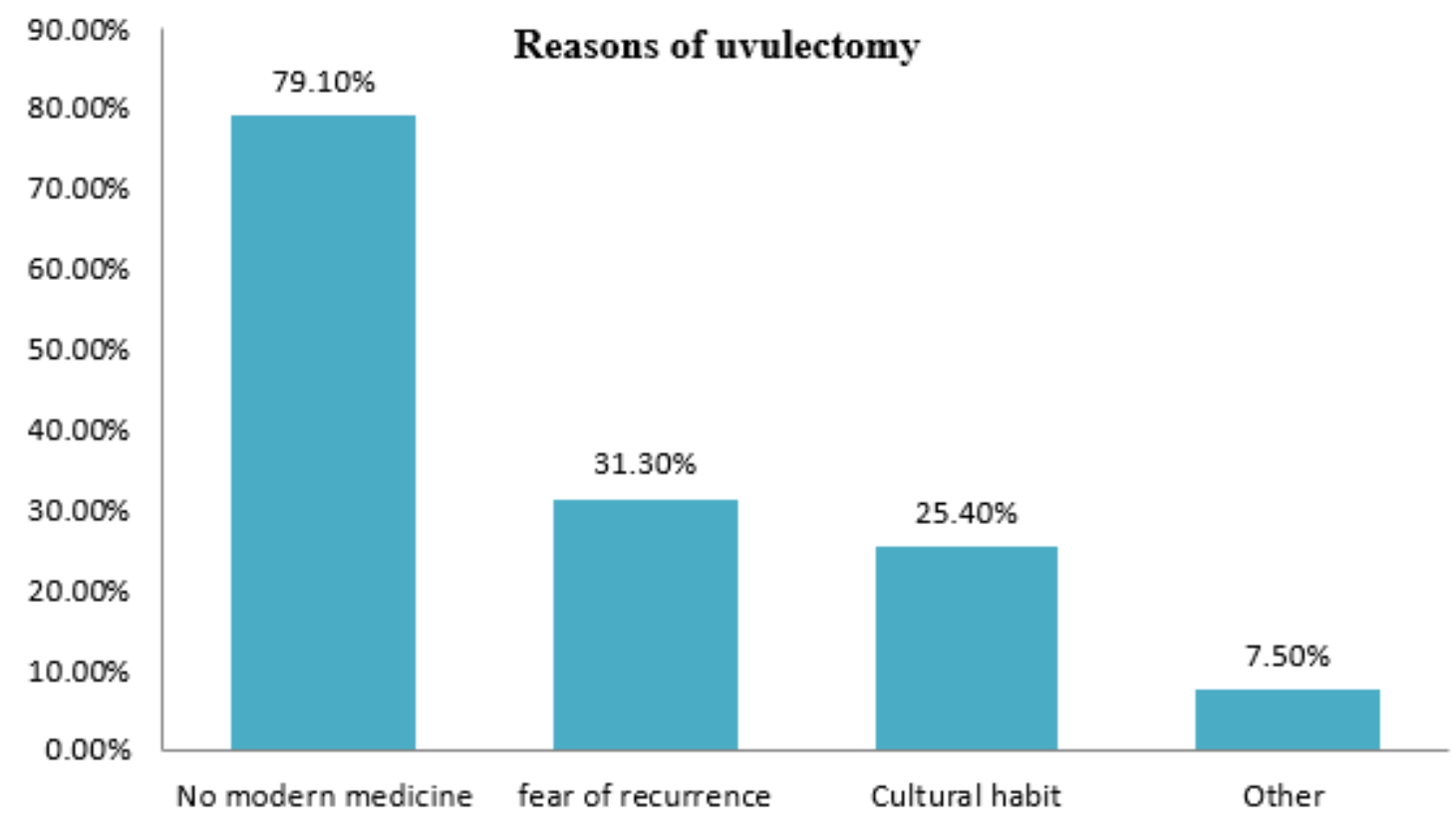

\section{Figure 3}

Reasons of traditional neonatal uvulectomy among the post uvulectomy admissions at Debre Tabor General Hospital, South Gondar Zone, 2019. 